\title{
LONG TERM LIDAR MEASUREMENTS OF AEROSOL PROPERTIES OVER THESSALONIKI
}

\author{
Nikolaos Siomos ${ }^{1,}{ }^{*}$, Kalliopi A. Voudouri ${ }^{1}$, Eleni Giannakaki ${ }^{2,5}$, Vasilis Amiridis ${ }^{3}$, Maria \\ Filioglou $^{1,2}$, Alexandros Papayannis ${ }^{4}$ and Dimitris S. Balis ${ }^{1}$ \\ ${ }^{1}$ Laboratory of atmospheric physics, Physics Department, Aristotle University of Thessaloniki, \\ Greece,*Email: nsiomos@physics.auth.gr \\ ${ }^{2}$ Finnish Meteorological Institute, Atmospheric Research Centre of Eastern Finland, Kuopio, \\ Finland \\ ${ }^{3}$ Institute for Astronomy, Astrophysics, Space Applications and Remote Sensing, National \\ Observatory of Athens, Athens, Greece \\ ${ }^{4}$ National Technical University of Athens, Physics Department, Laser Remote Sensing \\ Laboratory, Athens, Greece \\ ${ }^{5}$ Department of Environmental Physics and Meteorology, Faculty of Physics, University of \\ Athens, Greece
}

\begin{abstract}
In this study we present some first results on the potential of 15 years of lidar measurements over the lidar station of Thessaloniki to compile a climatology of the aerosol properties for the period 2001-2015. This is examined on a monthly, seasonal and annual basis. Both the profile structure and the columnar properties of the aerosol extinction and backscatter products are examined. The results are compared for consistency against co-located sunphotometer measurements.
\end{abstract}

\section{INTRODUCTION}

The Thessaloniki Lidar System (THELISYS) operates as a UV Raman and elastic lidar since 2000. The initial setup included a Raman channel at $387 \mathrm{~nm}$ and two elastic channels at $355 \mathrm{~nm}$ and 532nm. In 2008 a second Raman channel at $607 \mathrm{~nm}$ was added and in 2012 a third elastic channel at $1064 \mathrm{~nm}$ was included as well. The station participates in the European Lidar Network and measurements are conducted and processed systematically according to the network standards and schedule [1]. The measurements from the period 2001-2008 were analyzed and by [2] and [3] and focus mostly on the origin and typing of the observed aerosol layers. Here we analyze the long term variability of the aerosol backscatter and extinction coefficient at $355 \mathrm{~nm}$ during the period 20012015. The seasonality is analyzed for both the vertical profiles and the columnar optical depth (AOD). The AOD seasonality is also compared with sunphotometer data for consistency. The data processing procedure is described in detail in section 2 .

\section{METHODOLOGY}

The analysis is based on the aerosol extinction and backscatter profiles at $355 \mathrm{~nm}$ that were produced after processing with our operational algorithms that are following the EARLINET quality assurance procedures for the period 2001-2015. The extinction profiles are retrieved with the Raman inversion [4] and correspond solely to night time measurements. The elastic backscatter profiles that we present here are retrieved by applying the Klett inversion [5], that requires the assumption of a constant lidar ratio that is chosen from climatological values. The elastic backscatter profiles correspond to daytime measurements. All profiles are publicly available in the EARLINET database (doi:10.1594/WDCC/ 
EN_all_measurements_2000-2016). Due to hardware limitations in the lidar system, the profiles typically cover a variable altitude range for each measurement. To avoid this behavior we extent each profile down to the ground level, that is $60 \mathrm{~m}$ for Thessaloniki, assuming that the extinction and backscatter coefficients remain constant below the lower retrieved value. The monthly averages are calculated first and the seasonal averages are derived for the monthly averages. The lidar data availability, however, is neither constant nor always high for the analyzed periods. In order to examine if the averages are representative of the corresponding time period, data with higher temporal availability are required to be used as an independent reference. For this purpose, aerosol optical depth data from a co-located CIMEL sunphotometer are compared with the corresponding lidar values. The instrument is part of the Aerosol Robotic Network AERONET and the level 1.5 daily averages that are produced by the AERONET algorithms are used here. In order to achieve representative seasonal AOD values, averages of less than 10 days per month and less than 2 months per season were excluded from the analysis. Since the sunphotometer doesn't operate in the same wavelengths as the lidar, it is necessary to convert the AOD values using an angstrom exponent. For the $355 \mathrm{~nm}$ the sunphotometer AOD at $440 \mathrm{~nm}$ was converted using the angstrom 440-675nm in order to have the longest possible timeseries. The lidar ratio value that was used to retrieve each backscatter profile is applied in order to convert the integrated backscatter to AOD, mention later in the paper as backscatter based AOD. It is important to mention that unlike the Raman extinction profiles where the overlap of the lidar system is calculated and applied individually per case, the elastic backscatter product is not overlap corrected. The profiles are restricted above the full overlap height. This could affect the AOD values. The results of the analysis are pre- sented in section 3 .

\section{RESULTS}

Time height cross sections of the Raman extinction and elastic backscatter profiles at $355 \mathrm{~nm}$ are displayed in figure 1. Most of the aerosols are usually located below $5 \mathrm{~km}$ for the whole period. Higher values appear at the years 2001 to 2005 possibly affected by issues related to the higher overlap of the system during that period. A seasonal behavior is observed here. Higher values appear usually in the summer and lower values in the winter. Layers at higher altitudes are more frequent during summer. The

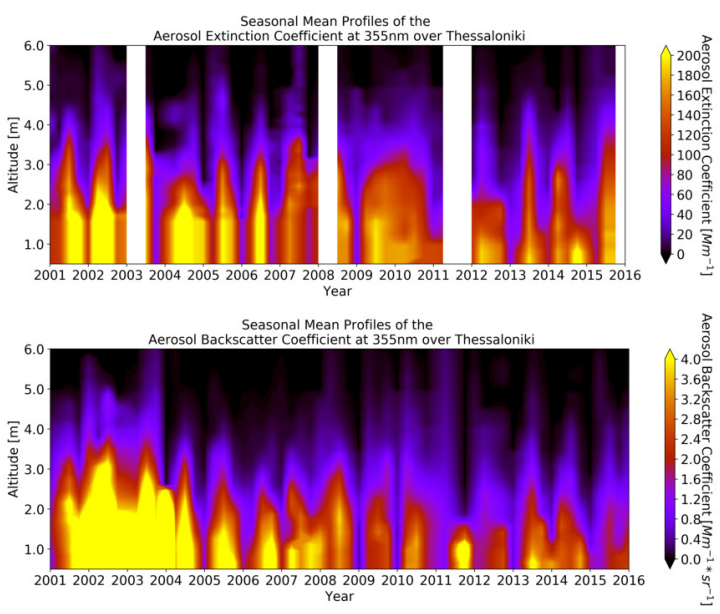

Figure 1: Seasonal mean time-height cross section of the aerosol extinction coefficient (upper panel) and the aerosol backscatter coefficient (lower panel) at $355 \mathrm{~nm}$ for the period winter 2001 to autumn 2015.

annual cycle from the whole period and the corresponding AOD values are presented in figures 2 and 3 respectively. Only months with more than 5 years of available data are included in the figures. The maximum values appear in the summer months, that is, August for the extinction profile and July for the backscatter profile. A secondary maximums appear in October. The extinction annual cycle also shows high values in March and April while a third maximum ap- 
pears in February of the backscatter annual cycle.
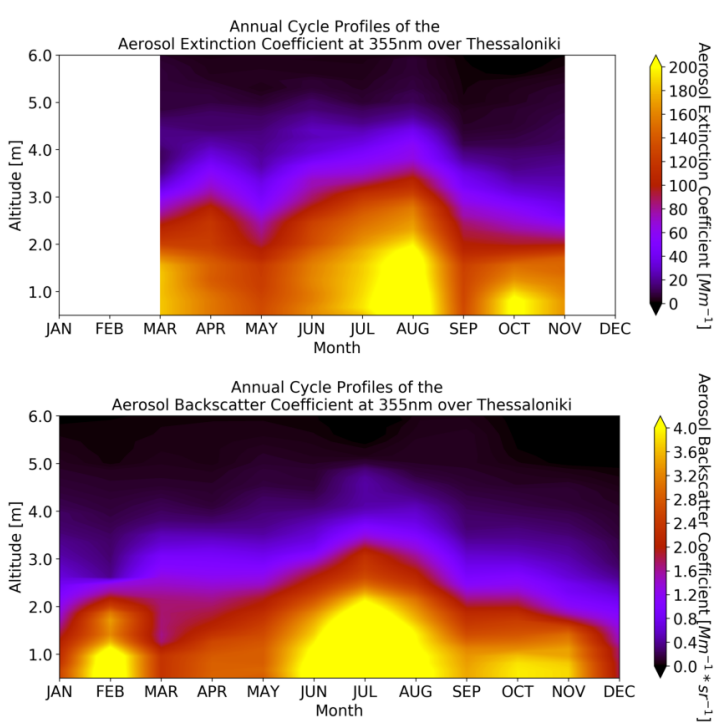

Figure 2: Mean annual cycle of the aerosol extinction coefficient (upper panel) and the aerosol backscatter coefficient (lower panel) at 355nm over Thessaloniki.

Differences could be attributed to the fact that the Raman extinction dataset contains only nighttime measurements while the elastic backscatter dataset contains mainly daytime measurements (see section 2). When compared with the sunphotometer annual cycle the agreement is best for April, May, October and November, as far as the lidar extinction AOD is considered. The maximum of the sunphotometer AOD also occurs during July but the lidar value is overestimated. Overall, the monthly variations of the annual cycle are reproduced from the lidar extinction AOD with the exception of September. As far as the backscatter based AOD is considered, February, May, Jun, August and October are the months that show the best agreement with the sunphotometer. The variability, however, of the February average backscatter based AOD is high. January, September and December are quite underestimated. Moreover, the secondary maximum
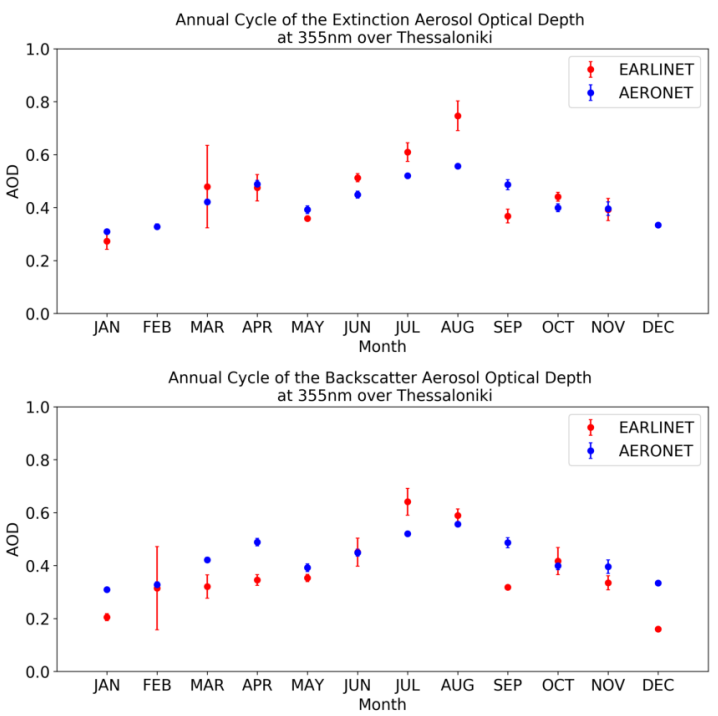

Figure 3: Comparison of the annual cycle calculated with the sunphotometer AOD at $355 \mathrm{~nm}$ and with the extinction (upper panel) and backscatter (lower panel) AOD at 355nm.

in April isn't reproduced. The lack of an overlap correction in the elastic backscatter profiles (see section 2) could explain the differences between the two lidar products.

Figure 4 shows the monthly (upper panel) and seasonal (lower panel) mean AOD timeseries from the lidar and the sunphotometer for the Raman extinction and the elastic backscatter based AOD at $355 \mathrm{~nm}$. We have chosen the period Autumn 2003 - Autumn 2015 in order to have comparable lidar and sunphotometer datasets. The least square fit line is calculated for both the AOD values. The sunphotometer trend is considered more accurate than the lidar trend since it is produced by higher temporal frequency data (see section 2). The trend based on the monthly means is $-11.2 \cdot 10^{-3}$ per year against $-9.6 \cdot 10^{-3}$ per year for the sunphotometer while the trend based on the seasonal means is $-12.4 \cdot 10^{-3}$ per year against $-10.1 \cdot 10^{-3}$ per year respectively. Despite the lower data availability of the lidar extinction dataset, the trends are well reproduced. 


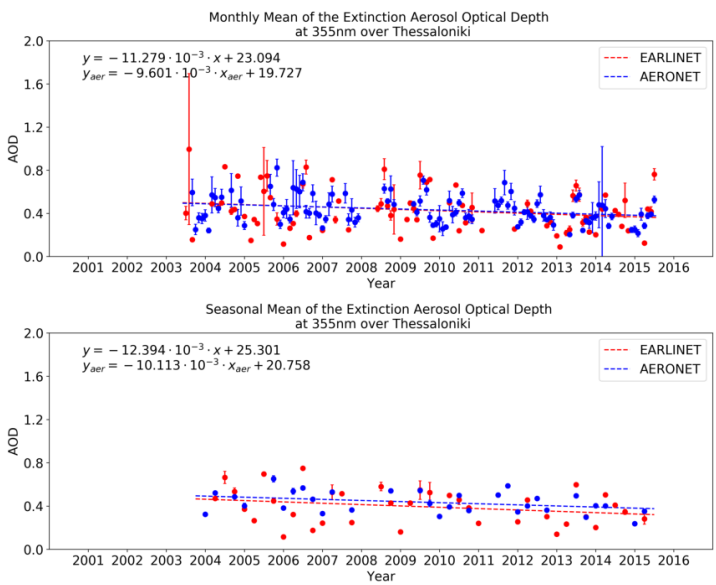

Figure 4: Comparison of the sunphotometer AOD at $355 \mathrm{~nm}$ and with the lidar extinction AOD at $355 \mathrm{~nm}$ based on the monthly mean (upper panel) and the seasonal mean (lower panel) values.

\section{CONCLUSIONS}

The analysis of the long term lidar measurements of Thessaloniki shows that the variable and usually limited availability and the different sampling of the climatological EARLINET lidar data provide consistent results with reference data. The comparison between the sunphotometer AOD and the lidar extinction AOD at $355 \mathrm{~nm}$ resulted in similar monthly and seasonal trends during the period 20031015. As far as the annual cycle is considered, the monthly variability of the lidar extinction is compatible with the sunphotometer one. Higher mean values appear during summer and the maximum AOD occurs in August. The agreement is best for April, May, October and November. By including more lidar products in the analysis, it is possible to investigate the trends of additional optical products such as the lidar ratio using the Raman backscatter product at $355 \mathrm{~nm}$ or the angstrom exponent $355 \mathrm{~nm}$ $532 \mathrm{~nm}$ using the elastic backscatter at $532 \mathrm{~nm}$. The clustering of the lidar measurements by their aerosol type using wind backward trajectories is also going to be implemented in the future.

\section{ACKNOWLEDGEMENTS}

This work has been conducted in the framework of EARLINET (EVR1 CT1999-40003), EARLINET-ASOS (RICA-025991) and ACTRIS-2 funded by the European Commission. This project has received funding from the European Union's Horizon 2020 research and innovation programme under grant agreement No 654109.

\section{References}

[1] G. Pappalardo, A. Amodeo, A. Apituley, A. Comeron, V. Freudenthaler, H. Linné, A. Ansmann, J. Bösenberg, G. D’Amico, I. Mattis, L. Mona, U. Wandinger, V. Amiridis, L. Alados-Arboledas, D. Nicolae, and M. Wiegner. Earlinet: towards an advanced sustainable european aerosol lidar network. Atmospheric Measurement Techniques, 7(8):23892409, 2014.

[2] V. Amiridis, D. S. Balis, S. Kazadzis, A. Bais, E. Giannakaki, A. Papayannis, and C. Zerefos. Four-year aerosol observations with a raman lidar at thessaloniki, greece, in the framework of european aerosol research lidar network (earlinet). Journal of Geophysical Research: Atmospheres, 110(D21):n/a-n/a, 2005. D21203.

[3] E. Giannakaki, D. S. Balis, V. Amiridis, and C. Zerefos. Optical properties of different aerosol types: seven years of combined ramanelastic backscatter lidar measurements in thessaloniki, greece. Atmospheric Measurement Techniques, 3(3):569-578, 2010.

[4] Albert Ansmann, Ulla Wandinger, Maren Riebesell, Claus Weitkamp, and Walfried Michaelis. Independent measurement of extinction and backscatter profiles in cirrus clouds by using a combined raman elastic-backscatter lidar. Appl. Opt., 31(33):7113-7131, Nov 1992.

[5] James D. Klett. Stable analytical inversion solution for processing lidar returns. Appl. Opt., 20(2):211-220, Jan 1981. 